\title{
Effect of metallic ions on the adhesion of biofilms formed by Pseudomonas fluorescens ${ }^{x}$
}

\author{
M.J. Vieira*, R. Oliveira, L. Melo, M.M. Pinheiro, V. Martins \\ University of Minho, CQPA/INIC, 4700 Braga, Portugal
}

(Received 11 February 1993; accepted 22 February 1993)

\begin{abstract}
Data on the adhesion of biofilms formed by Psetudomonas fluorescens to aluminium, copper and brass surfaces are reported in this paper. Biofilm thicknesses after $48 \mathrm{~h}$ were lower on the brass plates than on the other two metals. The results are compared with predictions of bacterial adhesion obtained by the method of van Oss et al. (C.J. van Oss. M.K. Chaudhury and R.J. Good, Chem. Rev., 88 (1988) 927), based on the evaluation of the change in the free energy of adhesion of the interacting systems. The presence of metallic lons released by the surfaces into the environment seemed to affect bacterial metabolism and adhesion and were taken into account to explain the discrepancies between experimental data and thermodynamic predictions. The possible effects of the extracellular polymers excreted by the bacteria on their attachment abilities are also stressed.
\end{abstract}

Key words: Adhesion: Biofilms: Metallic ions: Pseudomonas fluorescens

\section{Introduction}

Biofilms (communities of microorganisms adhering to surfaces, usually within a matrix of extracellular polymeric substances) are now a subject of great interest not only in engineering but also in medicine. As far as medicine is concerned, the formation of biological films on prostheses and implants can be a severe problem because even a slight bacterial contamination of an implant surface requires its replacement to avoid infection and rejection. The formation of the tooth plaque is another typical biofilm problem. In engineering. microbial films can also be responsible for undesirable effects, such as in heat exchangers, where they increase the thermal resistance and pressure drop.

\footnotetext{
* Corresponding author.

"The preliminary form of this paper was presented at the 7 th International Conference on Colloid and Surface Science held in Compiègne, France, 7-13 July 1991, and was coordinated for publication by Professors D. Muller and D. Labarre.
}

However, there are industrial situations where their formation is encouraged, as in the bioreactors used in water and waste-water treatments.

According to the mechanisms generally accepted to describe the build-up of biofilms [1], the first step appears to be the formation of a "conditioning film" of macromolecules on the solid surface, followed by the attachment of microorganisms, which grow, replicate and produce extracellular polymers that form a matrix containing the microbial species. Two other processes often involved in biofilm development are the adhesion of microorganisms to the biofilm surface and the detachment of parts of the microbial layer, particularly in flow systems.

Reliable predictions of microbial adhesion are of major importance in preventing undesirable biofilm formation, or in choosing the appropriate support materials for the adhesion of beneficial biofilms. A thermodynamic approach based on the change in the free energy during the adhesion process $\left(\Delta F^{\text {ad }}\right)$ has been widely used for predictive 
purposes [2-4], adhesion being expected to occur if $\Delta F^{\text {ad }}<0$. The latter is usually calculated with the individual values of the surface free energies of the interacting bodies, neglecting electrical charge effects and specific biochemical interactions. The determination of $\Delta F^{\text {ad }}$ is still the subject of great controversy: there are not only different methodologies available, but also different interpretations of the nature of the free energy of adhesion [5-7].

The most recent approach, proposed by van Oss et al, [8], considers the existence of two surface tension components: a dispersion component determined by all the three types of Lifshitz-van der Waals forces $\left(\gamma^{\mathrm{LW}}\right)$ and a polar component arising from interactions usually considered to be of the acid base type $\left(\gamma^{\mathrm{AB}}\right)$, comprising a hydrogen-accepting $\left(\gamma^{-}\right)$and a hydrogendonating $\left(\gamma^{+}\right)$parameter.

This kind of approach yielded satisfactory results in the prediction of bacterial adhesion to polymeric surfaces $[3,4,9]$, but its application to metallic surfaces may not be so straightforward, owing to the possible effects of the ions that the oxidized metals tend to release.

The purposes of this paper are then the assessment of the approach of van Oss et al. to predict bacterial attachment, and the investigation of the particular effects of metal surfaces on the initial adhesion and development of biofilms.

\section{Experimental}

\section{Organism}

Pseudomonas fluorescens, a bacterium present in natural waters, was used as a biofilm producer. The bacteria were kept in nutrient agar slants, and inoculated on $500 \mathrm{ml}$ of sterile medium composed of $0.5 \%$ glucose, $0.25 \%$ peptone and $0.125 \%$ yeast extract. They were allowed to grow at $27^{\circ} \mathrm{C}$, stirred at $130 \mathrm{rev} \mathrm{min}^{-1}$ in an orbital shaken incubator. The bacteria started to grow $8 \mathrm{~h}$ after inoculation, and kept growing for $8 \mathrm{~h}$.

\section{Biofilm production}

Biofilms of Pseudomonas fluorescens were formed on metallic surfaces - aluminium. copper and brass (an alloy of copper and zinc) - during $48 \mathrm{~h}$, under flow conditions. Briefly, the system was composed of a fermenter and a mixing vessel and a test cell with a rectangular deposition surface (area, $20 \mathrm{~cm}^{2}$ ). Pseudomonas fluorescens was continuously growing in the fermenter, in the medium described above, at $\mathrm{pH} 7$ and $27^{\circ} \mathrm{C}$. The temperature in the fermenter was maintained by a surrounding constant temperature bath. The $\mathrm{pH}$ was measured by a $\mathrm{pH}$ probe and controlled by adding $2 \mathrm{M} \mathrm{NaOH}$. The mixing vessel is 121 (volume filled with liquid) and is inoculated by bacteria grown in the fermenter to obtain a constant bacterial concentration of $6 \times 10^{7}$ cells per $\mathrm{ml}$. Water entered the mixing vessel at a flow rate of $101 \mathrm{~h}^{-1}$ (residence time of $72 \mathrm{~min}$ ). The temperature was also maintained at $27 \mathrm{C}$, and the glucose concentration at 20 p.p.m. by constant addition of the sterile medium described before. The $\mathrm{pH}$ was $6.5-7$.

The fluid contained in the mixing vessel (composed of water, 20 p.p.m. glucose and $6 \times 10^{7}$ cells per $\mathrm{ml}$ ) was pumped up through the experimental system, passing over the test section at a velocity of $0.13 \mathrm{~m} \mathrm{~s}^{-1}(R e=3300)$ and returning to the mixing vessel.

After $48 \mathrm{~h}$ of biofilm development, the test plates were removed, air dried and the thicknesses were measured using a micrometer [10] coupled to an electrical circuit. A significant number of thickness measurements were carried out so that reliable average values could be obtained. The thicknesses were measured with an accuracy of $\pm 5 \mu \mathrm{m}$.

\section{Growth rates}

The growth rates of Pseudomonas fluorescens in different medium conditions were determined using batch cultures.

Four flasks containing $500 \mathrm{ml}$ of the sterile medium composed of $0.5 \%$ glucose, $0.25 \%$ peptone and $0.125 \%$ yeast extract were inoculated with 
equal amounts of Pseudomonas fluorescens. One of the flasks - the control - contained only the growth medium. Each of the remaining three flasks received the same amount $\left(50 \mu \mathrm{g} \mathrm{ml}^{-1}\right)$ of one of the following cations: $\mathrm{Al}^{3+}, \mathrm{Zn}^{2 *}, \mathrm{Cu}^{2+}$.

The optical density of each medium was read at $640 \mathrm{~nm}$ over a period of $110 \mathrm{~h}$ and the extent of the lag phase and the growth rate were compared.

For each one of the above mentioned metallic ions, the whole procedure was repeated three times, obtaining three growth curves. The curves presented in Figs. 1-3 are then average curves (maximum deviation $5 \%$ ).

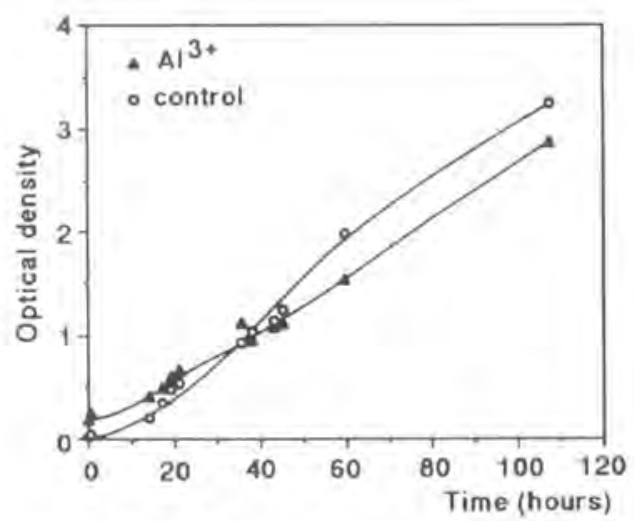

Fig. 1. Growth curve of Pseudomonus fluofescens in the presence of $\mathrm{Al}^{3-}$.

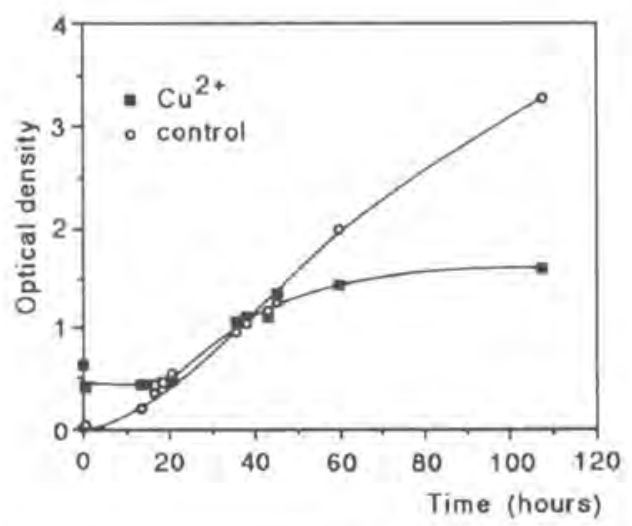

Fig. 2. Growth curve of Pseudomonas fluorescens in the presence of $\mathrm{Ca}^{2+}$

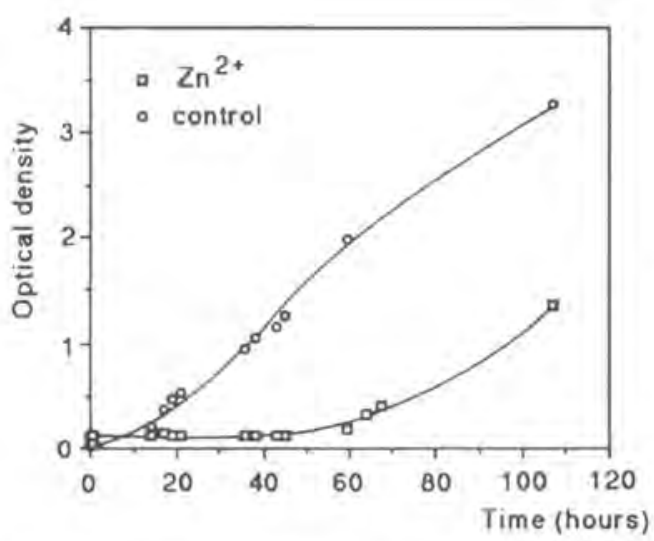

Fig. 3. Growth curve of Pscudomenas fluerescens in the presence of $\mathrm{Zn}^{2 \cdot}$

\section{Contact angle measurements}

Contact angle measurements were carried out using the sessile drop technique on lawns of Pseudomonas fluorescens, on metallic surfaces [10] and on biofilms formed on metallic surfaces. This technique was described in detail in Refs. 11 and 12.

\section{Results and discussion}

The thicknesses of biofilms formed on aluminium, copper and brass are presented in Table 1. Table 1 indicates that the biofilms formed on aluminium and copper have similar thicknesses (the differences being within the experimental error). whereas that formed on brass is thinner.

It seems useful to examine the results under the light of the predictive methods used in adhesion studies. Using the approach of van Oss et al. [8], the initial adhesion of "single" bacteria (i.e. bacteria not imbedded in a biofilm matrix) in the absence of nutrients was expected to be favourable in every

Table I

Thickness of biofilms formed on each metal plate, after $48 \mathrm{~h}$

\begin{tabular}{ll}
\hline Metal plate & Thickness $(\mu \mathrm{m})$ \\
\hline Aluminium & 50 \\
Copper & 55 \\
Brass & 33
\end{tabular}


case, and should be more pronounced on brass than on copper, and least on aluminium (Table 2).

In the present situation, the stream contained not only bacteria but also a significant amount of nutrients that stimulate bacterial growth and biofilm development. After a few hours, the deposition surface is not the metal plate anymore, but the biofilm itself. Another interaction energy must then be calculated, considering the following two bodies: bacteria and biofilm. For this purpose, contact angles were measured on biofilms and bacteria (Table 3).

Using the data shown in Table 3, the energy of interaction between bacteria and biofilm was evaluated by the method of van Oss et al. [8]. A value of $\Delta F^{\mathrm{ad}}=-14.6 \mathrm{~mJ} \mathrm{~m} \mathrm{~m}^{-2}$ was obtained, denoting that adhesion of Pseudomonas fluorescens to its own biofilm should always be a favourable process. This value of $A F^{\text {ad }}$ can be applied to the biofilms formed on the three metals, because the interacting bodies (bacteria and biofilm) are the same in every case, despite the different substrata that are supporting the microbial layers.

The results presented in Tables 2 and 3 do not justify the differences obtained in the thickness of

Table 2

Surface free energy of adhesion between bacteria and metallic surfaces $[8,13]$

\begin{tabular}{lc}
\hline Metal plate & $\Delta F^{\text {ad }}\left(\mathrm{mJ} \mathrm{m}^{-2}\right)$ \\
\hline Aluminium & -3.84 \\
Copper & -5.32 \\
Brass & $-13,90$ \\
\hline
\end{tabular}

Table 3

Contact angles of pure liquids on biofilms and on bacteria

\begin{tabular}{lll}
\hline Liquids & \multicolumn{2}{l}{ Contact angle (deg) } \\
\cline { 2 - 3 } & On biofilms & On bacteria" \\
\hline Water & 70.5 & 38 \\
Formamide & 36.7 & 30 \\
$x$-Bromonaphthaiene & 19.7 & 32 \\
Methylene iodide & 50.9 & 50 \\
\hline
\end{tabular}

"Psetudomonas fluoroscens. the biofilms. The metal ions released by the plates to the liquid medium and into the microbial layer may have an effect on bacterial adhesion and metabolism, so growth curves of Pseudomonas fluorescens were determined in the presence of different cations in the liquid phase. Figures 1-3 represent the average bacterial growth curves (optical density versus time) obtained in batch cultures containing (in separate flasks) $\mathrm{Al}^{3+}, \mathrm{Zn}^{2+}$ and $\mathrm{Cu}^{2+}$, respectively. (Note that zinc and copper are the main components of brass.)

Figures 1-3 show that the lag phase of Pseudomonas fluorescens is not delayed in the presence of $\mathrm{Al}^{3+}$, as compared to the control experiment. A short delay in the presence of $\mathrm{Cu}^{2+}$, and a long lag phase in the presence of $\mathrm{Zn}^{2+}$ can be observed.

However, Figs. 1-3 show that the growth rate in the exponential phase is not greatly reduced when there are $\mathrm{Al}^{3+}$ ions in solution, but highly reduced in the case of $\mathrm{Cu}^{2+}$. The effect of $\mathrm{Zn}^{2+}$ is rather peculiar: after a long lag phase (around $60 \mathrm{~b})$, bacteria seem to grow at a rate similar to the control rate (identical slope of the exponential part of the growth curve).

It is thought that even small quantities of ions released by the metallic surfaces can result in appreciable concentrations within the biofilm, because of the resistance to diffusion offered by the polymeric matrix.

Therefore, the apparent contradiction between Tables 1 and 2 could be explained by the fact that the aluminium ions do not seem to have a visible effect on the metabolic behaviour of Pseudomonas fluorescens, whereas the presence of copper and zinc ions leads to lower growth rates and longer lag phases. For instance, in the case of $\mathrm{Zn}^{2+}$ the lag phase is so long that even if a high number of bacteria managed to adhere to the surface in the first hours, initial biofilm development would be rather slow owing to the inhibitory effects of zinc. This could explain why the microbial layer formed after $48 \mathrm{~h}$ is still thinner than those formed on aluminium and copper.

Other phenomena can be considered to be 
involved in the process of adhesion and initial formation of microbial films. In fact, as reported by Meyer et al. [14], solid surfaces in contact with biological aqueous solutions rapidly (in a few minutes) become covered with macromolecules (e.g. glycoproteins) that modify the physical/chemical properties of the surface. This effect was not taken into account in the calculation of the energy of interaction between the bacteria and the metallic surfaces [8]. However. in the present experiments, in which a rather high concentration of nutrients is used, the amount of extracellular polymers produced by the microorganisms is considerable and this latter phenomenon may offset the effect of the so-called "macromolecular conditioning film". Although their role in adhesion is not yet fully understood, the polymers excreted by the bacteria appear to facilitate and reinforce microbial attachment to surfaces [15]. For instance, in biological systems, "polymer molecular chains" have been observed on both surfaces (the support and the bacteria), forming a "polymer bridge" between the two interacting bodies $[16,17]$. Therefore, in the cases in which the metabolism is not affected by the presence of metallic ions, the ability of microorganisms to adhere and grow during the first stage of biofilm development will be favoured as compared to the cases in which inhibitory effects are involved.

\section{Concluding remarks}

The initial formation of biofilms on surfaces cannot be seen as a simple physical interaction between bacteria and a solid support. The effects of the macromolecular conditioning film and/or of the biopolymers produced by the microorganisms must be taken into account, the latter being particularly important when significant amounts of nutrients are in solution.

Furthermore, when the solid support is a metal, its ions may be released to the environment and affect the metabolism of microorganisms, modifying their behaviour as far as adhesion and biological growth are concerned. Possibly, this explains why the thermodynamic approaches used to predict adhesion have been quite successful when the substrata are of polymeric nature, but not when the solid surface is a metal.

The results presented in this paper seem to indicate that whereas metallic ions such as $\mathrm{Zn}^{2+}$ and $\mathrm{Cu}^{2+}$ interfere with the initial adhesion and development of biofilms formed by Pseudomonas fluorescens, no such effects are detected when aluminium ions are present. These results confirm that the methodologies used to predict adhesion do not yet fully account for the special characteristics of the microbial surfaces and the particularities they may display when subjected to different environments.

\section{Acknowledgement}

The authors are grateful to JNICT, Portugal for financial support to the research work through project No. 87509 .

\section{References}

I W.G. Characklis, Bioflim processes, in W.G. Characklis and K.C. Marshall (Eds.), Biofilms, Wiley-Interscience, London, 1990, p. 195.

2 D.R. Absolom, F.V. Lamberti, Z. Policova. W. Zinge C.J. van Oss and A.W. Newmann. Appl. Environ. Microbiol., 46(1) (1983) 90 .

3 I.H. Pratt-Terpstra, A.H. Weerkamp and H.J. Busscher. J. Dent. Res., 68 (1989) 463.

4 M.N. Bellon-Fontaine, N. Mozes, H.C. van der Mei, J. Sjollema, O. Cerf, P.G. Rouxhet and H.J. Busseher, Cell Biophys., 17 (1990) 93.

5 J.K. Spelt and A.W. Neumann, Langmuir, 3 (1987) $58 \mathrm{X}$

6 H.J. Busscher and A.W.J. van Pelt, J. Mater. Sei. Lett. 6 (1987) 815.

7 C.J. van Oss, R.J. Good and M.K. Chaudhury, Langmuir. 4 (1988) 884.

8 C.J. van Oss, M.K. Chaudhury and R.J. Good. Chem. Rev., 88 (1988) 927.

9 G. Reid, H.S. Beg, C.A.K. Preston and L.A. Hawthorn. Biofouling, 4 (1991) 171.

10 M.M. Pinheiro. L.F. Melo, T.R. Bott. J.D. Pinheiro and L. Leitão. Can. J. Chem. Eng.. 66 (1988) 63.

If H.J. Busscher, A.H. Weerkamp, H.C. van der Mei, A.W.J. van Pelt, H.P, de Jong and J. Arends, Appl. Environ. Microbiol, 48 (1984) 980)

12 I.H. Pratt-Terpstra, A.H. Weerkamp and H.J. Busscher. Curr. Microbiol., 16 (1988) 311 . 
13 M.J. Vieira, R. Oliveira, L, Melo, M. Pinheiro and H.C van der Mei, J. Dispersion Sci. Technol., 13 (1992) 437.

14 M.E. Meyer, R.E. Baier and R.W. King, Can. J. Chem. Eng., 66 (1988) 55

I5 I.D. Robb, Stereo-biochemistry and function of polymers, in K.C, Marshall (Ed,), Microbial Adhesion and Aggregation, Springer-Verlag, Berlin, 1984, p. 39.
16. R, Oliveira, Physico-chemical aspects of adhesion, in L. Melo, T.R. Bott, M. Fletcher and B. Capdeville (Eds.). Biofilms Science and Technology, Kluwer Academic, Dordrecht, 1992, p. 45.

17 P.R. Rutter and B. Vincent, Physicochemical interactions of the substratum, microorganisms, and the fluid phase, in K C, Marshall (Ed.), Microbial Adhesion and Aggregation. Springer-Verlag, Berlin, 1984, p. 21. 